\title{
CURRÍCULO INTERCULTURAL CRÍTICO NA ESCOLA: Formação que produz diferenças
}

Darianny Araújo dos Reis ${ }^{(*)}$

Nas últimas décadas, inúmeras transformações, decorrentes de um dinâmico movimento - da globalização em suas matizes econômica, política e cultural, das ciências e das tecnologias de comunicação e informação e das novas facetas do capitalismo - tem incidido nas mais diferentes relações sociais. A sociedade contemporânea assiste a configurações de novos cenários sociais, nos quais as diferenças culturais, riqueza potencial das realidades humanas, adquirem cada vez mais centralidade na discussão política sobre as formas de ser e estar no mundo e, particularmente, colocam à educação escolar e às práticas pedagógicas demandas e desafios que envolvem o necessário entrecruzamento entre políticas de igualdade e políticas de diferença (Candau, 2008, 2016). Tal entrecruzamento opera sob tensão e conflitos, visto que está atravessado por constantes lutas sociais, ideológicas e de poder. Em especial, no campo cultural, cada vez mais manifestam-se afirmações de caráter étnico, religioso, de classes ou de gênero das minorias historicamente subalternizadas e excluídas que visam garantir direitos e reconhecimento.

Sendo um tema fraturante no meio social, as lutas das minorias, por um lado, despertam olhares bastantes sensíveis onde é possível vislumbrar mobilizações no âmbito de instituições e movimentos organizados da sociedade civil, no sentido de combater formas de discriminação, de fortalecer e ampliar políticas, ações e estratégias de participação cidadã e inclusão social. Por outro, também provocam reações de cunho conservador, geradores de violência, ódio e segregação. Daí ser tão urgente a contribuição que a escola pode oferecer no esforço para (re)construir projetos educativos e curriculares consistentes e democráticos.

O artigo chama a atenção para a necessidade de densificar a reflexão sobre a escola, instituição a serviço da formação dos(as) alunos(as), na qual não lhe pode escapar, dentre outros aspectos, que suas atribuições voltem-se à responsabilidade social de provocar, permanentemente, a leitura crítica da realidade, diversa e plural, da qual faz parte. Sendo assim, importa perceber o movimento dialético e contraditório que se dá nas relações e interações entre os seus mais diferentes

\footnotetext{
${ }^{(*)}$ Pedagoga, atualmente na função de assessora pedagógica na Divisão de Ensino Fundamental-SEMED/Manaus. Especialista em Metodologia do Ensino Superior pela Universidade Federal do Amazonas e especialista em Desenvolvimento Curricular e Inovação Educativa pela Universidade do Minho/PT. Mestre em Educação, PPGEUFAM. Doutoranda em Ciências da Educação pela Universidade de Trás-os-Montes e Alto Douro/Portugal. E-mail: darypedagoga@hotmail.com.
} 
sujeitos, partícipes e inseridos num espaço-tempo histórico que reclama uma educação sempre atenta aos mecanismos de homogeneização e uniformização ocultadores das diferenças culturais. Aportando-nos em Fleuri (2000, 2003, 2009), Candau (2000, 2002, 2006, 2008, 2016), Moreira e Candau $(2003,2008)$ argumentamos a favor do necessário estímulo à concretização de um currículo intercultural e criticamente orientado na direção de uma formação que se deseja diversa, dialógica e solidária, que não se trata apenas de aceitar que existem "outros diferentes", mas de valorizar as identidades e as subjetividades como processos que se constroem e ressignificam nas interações e aprendizagens com o outro.

Pensar um currículo que incorpore a perspectiva intercultural crítica como princípio formativo pressupõe que as diferenças culturais sejam assumidas como "polifonia da representatividade", ou seja, que questões como: conhecimento, saberes, corporeidade, linguagens, narrativas, relações, tempo, espaço traduzam-se como legítimos componentes na criação e recriação curricular.

\section{CULTURA, EDUCAÇÃO E CURRÍCULO}

Não há como dissociar educação e cultura, uma vez que o universo escolar, além de político e social, é também cultural. Na ação pedagógica mais imediata, os sujeitos transmitem seus sistemas de valores e de símbolos, suas diferentes vivências e linguagens, suas memórias, seus conceitos de mundo e de sociedade, posto que este processo consiste numa ação cultural. Obviamente que nesta ação os conflitos e as tensões estão presentes, pois a diversidade de sujeitos coloca em relevo afirmações de identidades.

A cultura é criação humana, constituindo-se num processo dinâmico e ativo, portanto, histórico. Pensar a escola distanciada de sua natureza cultural, por certo, é destituí-la de sua dimensão humana. A dimensão humana depende da cultura. Isto não significa que o elemento cultural seja o mais importante a ser considerado para a compreensão dos processos educativos que se dão no interior da escola. Contudo, o que não se pode ignorar é que estes mesmos processos estão atravessados pela circularidade das culturas.

A escola congrega experiências culturais múltiplas, porém, muitas delas invisibilizadas. Considerando que, muitas vezes, como historicamente observado, estas experiências culturais realizaram-se no sentido da imposição de padrões culturais universais, monolíticos e hegemônicos, é preciso afirmar a importância da cultura para a compreensão da escola e do que se desenvolve no seu cotidiano, conforme pondera Candau (1997, p. 240): 
Não se trata de assumir uma postura marcadamente culturalista, que vele os componentes ideológicos ligados à estrutura de classe e aos componentes estruturais determinantes da sociedade. No entanto, trata-se de dar ao componente cultural a atenção devida e superar toda perspectiva de reduzi-lo a um mero subproduto ou reflexo da estrutura social vigente na nossa sociedade. Afirma-se cada vez mais a consciência de que se trata de uma dimensão configuradora do ser humano em níveis profundos, no nível pessoal e coletivo.

A diversidade cultural que enseja em formas distintas de ver e conhecer o mundo faz da escola um lugar complexo. Complexidade que tem sido encarada quer de modo difuso e opaco, quer alienado ou indiferente. E, desta maneira, trata-se de pôr em marcha o pensamento crítico e reconstrutivo acerca da sociedade na qual estamos inseridos, em especial, a brasileira, já que está fortemente marcada por um passado de colonização e de exploração traduzido em processos de discriminação e "apagamento" das alteridades. Imersa numa cultura mais geral, a escola integra um conjunto de valores, hábitos, crenças, procedimentos, discursos e sentidos que legitima sua cultura particular: a cultura escolar. Nestes termos, a cultura escolar assume um papel fundamental na manutenção e/ou transformação de práticas segregadoras e discriminatórias. Aqui reside a preocupação de se problematizar as bases educativas homogeneizadoras que sustentaram a escola, amalgamadas na cultura ocidental e eurocêntrica e que ainda persistem no tradicionalismo institucional. Isto porque atinge hierarquicamente, logo à partida, outras culturas, saberes e vozes que figuram à margem ou na esfera da subalternização.

Candau (2000, p. 53), quando reflete sobre a cultura escolar cristalizada na escola, aponta que a "cultura escolar predominante nas nossas escolas se revela como "engessada", pouco permeável ao contexto em que se insere, aos universos culturais das crianças e jovens a que se dirige e à multiculturalidade das nossas sociedades". Por este prisma, a monoculturalidade nos currículos e nas práticas escolares tem presença marcante e um sentido político e ideológico em que é preciso contestar, a fim de que sejam contidos os efeitos de reprodução social. Daí que os "dispositivos de diferenciação pedagógica"1 , como propõe Cortesão (2012), ao serem incorporados nos currículos, visam contemplar uma gama mais vasta de possibilidades educativas a partir da construção curricular que se desenvolve na escola.

Cultura, sociedade e escola estão em relação geradora mútua. Nessa relação, não podemos perder de vista as interações entre indivíduos, eles próprios portadores/transmissores de cultura, que

\footnotetext{
${ }^{1}$ Segundo Cortesão (2012, p.731), os Dispositivos de Diferenciação Pedagógica (DDP) são aqueles materias e recursos "concebidos na periferia do sistema educativo, apelando à colaboração dos alunos, num quadro em que se tem em conta a sua heterogeneidade sócio-cultural, os seus diferentes problemas e conhecimentos com os quais o professor terá de saber lidar".
}

Revista Teias v. 18, n. 50, 2017 (Jul./Set.): Conversas sobre formação de professores, práticas e currículos 
regeneram a sociedade, a qual regenera a cultura (MORIN, 1998, p. 23). É possível dizer que, é por meio da cultura que os sujeitos informam a visão que têm do mundo e da compreensão sobre ele. A cultura por seu caráter dinâmico e sua pró-atividade possibilita que os mesmos sejam, numa perspectiva dialética, produtos e produtores da cultura. Partilhando da visão de Morin (2002, p. 56):

[...] a cultura é constituída pelo conjunto dos saberes, fazeres, regras, normas, proibições, estratégias, crenças, ideias, valores, mitos, que se transmite de geração em geração, se reproduz em cada indivíduo, controla a existência da sociedade e mantém a complexidade psicológica e social. Não sociedade humana, arcaica ou moderna, desprovida de cultura, mas cada cultura é singular. Assim, sempre existe a cultura nas culturas, mas a cultura existe apenas por meio das culturas.

A este propósito, cabe ressaltar que diferentes abordagens sobre a cultura ou as culturas propõem referências diversificadas no que tange à compreensão do conceito, uma vez que está diretamente ligado a processos tensos e conflitivos desenvolvidos na sociedade, nas relações no grupo e entre os grupos sociais e culturais. Para Geertz (1989), a cultura tem essencialmente um caráter semiótico, ou seja, a cultura é vista como sistema entrelaçado de signos interpretáveis, à procura de significado, portanto, um contexto que pode ser descrito e reescrito. Sendo assim, observa a cultura como, "um sistema de concepções herdadas, expressas em formas simbólicas por meio das quais os homens comunicam, perpetuam e desenvolvem seu conhecimento e suas atividades em relação à vida" (idem, p. 23).

Nesta perspectiva, a cultura permite ao sujeito dar sentido às suas experiências sociais e aos seus contextos de relações. E, desta forma, está especialmente associada à vida material e social dos sujeitos. As manifestações culturais descortinam o que nelas há de essencial: as diferenças. Segundo Freire e Faudez (1985, p. 31), as diferenças "nos ajudam a compreender a nós mesmos e a nossa própria cotidianeidade". Elas marcam a complexidade que representa o meio sociocultural. A cultura, como poder simbólico, exprime relações de forças, assimetricamente constituídas. Não obstante, a cultura tem o "poder de construção da realidade que tende a estabelecer uma ordem gnosiológica [...] poder de constituir o dado pela enunciação, de ver e fazer crer, de confirmar ou de transformar a visão de mundo e, deste modo, a ação sobre o mundo, portanto, o mundo (BOURDIEU, 1989, p. 9). Por este argumento as culturas estão permanentemente sendo reelaboradas, reconstruídas, sofrendo constantes processos de redefinições porque assim também acontecem as relações sociais. Não estão acabadas para que sejam prontamente consumidas ou transmitidas, mas estão coadunadas à produtividade humana, à fertilidade dos processos sociais. Esses processos realizam-se num contexto permeado por tensões, conflitos, contestação, poder e transgressão (SILVA, 1995), logo, não são neutros e, sobretudo, não estão esvaziados/deslocados 
ideologicamente. O recrudescimento de sua importância, cada vez maior na escola - espaço sociocultural revelador, por excelência, das diferenças culturais (étnicas, religiosas, de classe, de gênero ou geracionais) - reflete-se nos discursos e práticas pedagógicas, particularmente, na produção do currículo escolar.

\section{A PERSPECTIVA INTERCULTURAL CRÍTICA}

Se, por um lado, os processos culturais engendrados num contexto de globalização têm forjado padrões uniformizadores entre os estilos de vida e alicerçados num forte consumismo, por outro lado, a tendência à homogeneização tem contrastado com a produção de identidades locais, de diferentes grupos de minorias culturais que reforçam a ascensão dos movimentos de luta pela afirmação das diferenças como um direito inalienável. Neste cenário, podemos observar uma ampla heterogeneidade cultural coexistindo a partir do velho e do novo, do moderno e do tradicional, do universal e do particular, do local e do global associada a sujeitos que não mais se definem por identidades fixas, estáveis, mas por identidades que estão constantemente sendo desestabilizadas, deslocadas e fragmentadas, portanto, pela "descentração do sujeito" na modernidade tardia (HALL, 1997). É um panorama no qual acentua as diferentes expressões culturais que constituem os sujeitos nas tramas de uma sociedade destacada por seu pluralismo.

A perspectiva intercultural crítica confere-nos um aporte teórico que não está fechado em si mesmo, ao contrário (FLEURI, 2000). O debate em torno desta perspectiva nos conduz a um arcabouço teórico-conceitual bastante plural, por vezes, ambíguo ou dicotômico. No que tange à educação escolar, a posição intercultural crítica apoia-se numa mudança de paradigma que põe em causa o pensamento monocultural, sendo este último considerado simplificador e contraproducente, uma vez que procura eclipsar as diferenças existentes e manter verdades absolutas. Ademais, a perspectiva intercultural crítica conjugada ao currículo busca fomentar concepções, estratégias, métodos e ações educativas fundamentadas em valores substancialmente relevantes para o desenvolvimento de sociedades democráticas e mais justas, tais como a solidariedade e a equidade, coadunados a um sentido ético e político. Como assinala Fleuri (2000, p. 5), a perspectiva intercultural crítica

[...] emerge no contexto das lutas contra os processos crescentes de exclusão social. Surgem movimentos sociais que reconhecem o sentido e a identidade cultural de cada grupo social. Mas, ao mesmo tempo valorizam o potencial educativo dos conflitos. E buscam desenvolver a interação e a reciprocidade entre grupos diferentes, como fator de crescimento cultural e de enriquecimento mútuo.

Revista Teias v. 18, n. 50, 2017 (Jul./Set.): Conversas sobre formação de professores, práticas e currículos 
Mais do que o reconhecimento e a valorização das diferenças culturais, a perspectiva intercultural crítica preconiza o diálogo democrático entre os grupos socioculturais, compreendendo que nesse processo há um complexo campo de confrontos e de enfrentamentos. No seguimento desta ideia, "a perspectiva intercultural de educação pode, ainda, estimular os movimentos sociais a focalizar, na própria reflexão e na própria prática, a dialética identidade/alteridade. Ou seja, estimular a consciência das diferenças e das relações entre os agentes e os pontos de vista que nele se articulam" (idem, p. 7). Desta maneira, o autor aponta para três aspectos importantes que permitem compreender esta perspectiva.

O primeiro diz respeito à intencionalidade. A intencionalidade atravessa a relação entre grupos culturais diferentes, pressupondo a construção de um projeto educativo deliberado participativamente em que deve garantir a promoção da relação entre pessoas de culturas diferentes. O segundo aspecto que distingue a educação multicultural da intercultural volta-se "aos diferentes modos de se entender a relação entre culturas na prática educativa" (idem, p. 9). Segundo o autor, na perspectiva multicultural as culturas diferentes são entendidas como se constituíssem objeto de estudo, ou seja, absorvidas como matérias a ser aprendida. Em contrapartida, na perspectiva intercultural a interação entre culturas diferentes dá-se mediante um processo complexo, permeado por modos dissonantes de ver o mundo, produzindo confrontos que podem possibilitar a modificação da maneira como uma pessoa ou grupo percebe a realidade em que está imersa. $\mathrm{O}$ terceiro relaciona-se a ênfase nos sujeitos da relação. Neste caso, a perspectiva intercultural valoriza os sujeitos das culturas como seres ativamente (re)criadores e, por conseguinte, sujeitos concretos, históricos que alimentam a cultura e são por ela realimentados/transformados. Daí se torna fundamental enfatizar que é uma perspectiva na qual se busca trabalhar a favor das relações entre as pessoas.

Especificando a perspectiva intercultural, Candau (2000, p. 23) elenca algumas de suas características, dentre outras: a) Promove deliberadamente a inter-relação entre diferentes grupos culturais presentes em uma determinada sociedade; b) Concebe as culturas em contínuo processo de elaboração, de construção e reconstrução; c) Afirma ser os processos de hibridização cultural intensos e mobilizadores da construção de identidades abertas, em construção permanente, o que supõe que as culturas não são "puras"; d) Endossa a consciência dos mecanismos de poder que permeiam as relações culturais; e) Não desvincula as questões da diferença e da igualdade presentes hoje de modo particularmente conflitivo, tanto no plano mundial quanto em cada sociedade.

Como expressão do que acima está registrado, a perspectiva intercultural crítica anuncia, por isso, reinventa uma educação que reconhece o "outro", que promove o diálogo, que "negocia e 
enfrenta os conflitos provocados pela assimetria de poder entre os diferentes grupos socioculturais, mas que é capaz de favorecer a construção de um projeto comum, pelo qual as diferenças sejam dialeticamente construídas" (idem, p. 23). Nela tem-se a consciência de que o diálogo estabelecido com o "outro" pressupõe desigualdades e confrontos por se imbricarem às assimetrias de poder, pois, muitas vezes, o "outro" está relacionado de maneira subalternizada ou hierarquizada (superiores e inferiores), é visto negativamente por representar uma ameaça ao "eu" ou "nós".

Em Moreira e Candau (2003) encontramos argumentações críticas a respeito da dificuldade que tem a escola de tratar da questão das diferenças culturais, indicando o persistente silenciamento e a neutralidade, mais do que a disponibilidade de abrir-se e ocupar-se com elas. Posto isto, a educação intercultural ainda é uma questão por se materializar, já que a reiteração de práticas não problematizadoras tem lugar cativo e se justifica, em boa parte, pelo desconhecimento de estratégias efetivas que possam no cotidiano escolar induzir mecanismos contra-hegemônicos, especialmente, quando a diversidade cultural se impõe no embate do espaço-tempo instituído.

Romper a dicotomia existente entre o espaço-tempo instituído e o espaço-tempo instituinte exige questionar e pensar a tradução e (re)criação de experiências e fazeres outros que não sejam os que a escola está habituada, compartilhando, assim, a riqueza de uma realidade que comporta outros mundos possíveis; modos de ler, sentir, falar, compreender singularizadores das identidades que, por sua vez, não são essencializadas, mas produzidas numa ordem social e construção cultural situada.

Através do recrudescimento da importância do elemento cultural para o estudo do universo escolar e de seu conteúdo curricular, é possível verificar que, de fato, a escola tem marcas sociais e culturais entranhadas e fixadas em sua estrutura, em seu funcionamento, em suas práticas internas, em sua materialidade que necessitam de um olhar atento, a fim de que parâmetros de dominação, sujeição ou exclusão não sejam naturalizados e replicados acriticamente. A cultura escolar, pela via da monoculturalidade, servirá para absolutizar conhecimentos e saberes que, com efeito, preservam o status quo dominante. Contrapondo-se à lógica monocultural, Candau (2000, p. 52) destaca que

[...] as nossas salas de aula, onde pretensamente se ensina e se aprende deveriam ser espaços de lidar com o conhecimento sistematizado, construir significados, reforçar, questionar e construir interesses sociais, formas de poder, de vivências que têm necessariamente uma dimensão antropológica, política e cultural.

Examinar os padrões culturais estabelecidos na lógica de funcionamento, estrutura e organização da escola, bem como os seus reflexos nos currículos e nas salas de aula, e ter por objetivo a promoção de ações educativas fundadas em constante reflexão e autorreflexão, pode 
significar um passo fecundo na (re)formulação de ferramentas de luta contra qualquer tipo de exclusão ou reprodução de desigualdades em contexto escolar. As salas de aula são espaços privilegiados para que as demandas sociais e culturais que as revestem possam conferir de modo considerável a forma e o conteúdo do currículo escolar.

O currículo constitui-se veículo potencial no fomento da perspectiva intercultural crítica nas instituições escolares por estar intrinsecamente vinculado aos percursos formativos dos(as) alunos(as). Mas é preciso entender que os sujeitos reais dão significados diferenciados às suas experiências educacionais à luz das suas vivências pessoais e sociais, muitas vezes, contrastantes com a cultura convencionalmente reproduzida nos espaços-tempos da escola. Desse ponto de vista, a educação intercultural abarca a complexidade das experiências humanas, delineadas e circunscritas a partir de modos culturais diversos no interior de um universo histórico e social mais abrangente.

\section{A PERSPECTIVA INTERCULTURAL CRÍTICA COMO PRINCÍPIO CURRÍCULAR}

O currículo escolar é uma construção sociocultural e histórica situada no tempo e no espaço, deste modo, diferentes discursos sobre o currículo são produzidos em tempo e espaço diferentes. $\mathrm{O}$ currículo significa intencionalidades e práticas, indo além da transmissão de um conjunto de conteúdos, valores e habilidades a ser ensinados. Constitui-se num campo de relações de poder, arena de contestação, de conflitos e em permanente redefinição, uma vez que prefigura, como postula Silva (2001), inter-relações entre saber, poder e identidade, isto é, por não ser neutro, o currículo prende-se precisamente com o que se deseja formar ou conformar. Dito de outra forma, tem a ver com a construção identitária do(a) aluno(a), sujeito interlocutor na construção curricular. Dada a polissemia do termo currículo, qualquer definição fechada traz em si conotação reducionista. Entretanto, sem a intenção de restringir o conceito, mas no sentido de situarmo-nos politicamente e levando em consideração o contexto escolar, acolhemos a ideia do currículo, na acepção apontada por Pacheco (2005, p. 9), isto é, para o autor "é um projecto com itinerários de formação; é um projecto cultural com identidades no tempo histórico e no espaço social da sua construção; é um projecto ideológico que ocorre no contexto de uma dada organização", sendo assim, no encalço destas ideias, o currículo remete-nos para a concepção de um projeto formativo, comparticipado entre vários intervenientes e de responsabilidades e poderes partilhados (Pacheco, 2005; Morgado, 2013). Coadunando-nos com a perspectiva referida, importa acrescentar o enfoque apresentado por De Alba (1998, apud RIGAL, 2000, p. 190) que entende o currículo como: 
[...] síntese de elementos culturais (conhecimentos, valores, costumes, crenças, hábitos) que estabelecem uma proposta político-educativa destinada a gerar significado e sentido para a vida social impulsionada por diversos grupos e setores sociais cujos interesses são diversos e contraditórios, ainda que alguns tendam a ser dominantes ou hegemônicos e outros tendam a opôr-se a tal dominação ou hegemonia; chega-se a essa síntese por meio de diversos mecanismos de negociação e imposição social.

Nesta perspectiva, o território da escola como uma arena sociocultural, acaba sendo o espaço onde há, inevitavelmente, processos de encontros/desencontros culturais. Teoricamente, os avanços na discussão do caráter plural da educação são significativos, seja retrospectiva ou prospectivamente, porém, no plano prático, a escola brasileira, salvo exceções, ainda se alicerça numa linha monocultural e universalista (MOREIRA; SILVA, 1995). As barreiras impostas, às vezes de forma sútil, pela cultura curricular acadêmica que, historicamente perpetua e reproduz os parâmetros hegemônicos dos conhecimentos socialmente aceitos e legitimados, dá lugar ao silenciamento dos grupos sociais e culturais minoritários, particularmente, de seus saberes e valores. De acordo com Santomé (1995, p. 161) “as culturas ou vozes dos grupos sociais minoritários e/ou marginalizados que não dispõem de estruturas importantes de poder costumam ser silenciadas, quando não estereotipadas e deformadas, para anular suas possibilidades de reação”.

O autor, ao perscrutar sobre as culturas/vozes silenciadas e a cultura da padronização faz notar o fato de, sendo a escola um espaço de convivência e sociabilidades, o exercício da alteridade não pode prescindir da liberdade de ideias, de pensamentos e da própria (re)construção do conhecimento que se realiza na relação com o outro, considerando as próprias idiossincrasias dos sujeitos. As contradições e conflitos que corporificam e atuam cotidianamente no espaço escolar podem contribuir para a reestruturação significativa de um projetor curricular mais democrático e inclusivo, desde que se construam espaços de escuta e participação ativa em que caibam as diferentes vozes no/do currículo escolar, invertendo, assim, a tradição de hierarquização e de poder:

Entender a voz do estudante é lidar com a necessidade humana de dar vida ao reino dos símbolos, linguagem e gestos. A voz do estudante é um desejo, nascido da biografia pessoal e da história sedimentada; é a necessidade de construir-se e afirmar-se em uma linguagem capaz de reconstruir a vida privada e conferir-lhe significado, assim como de legitimar e confirmar a própria existência no mundo. Logo, calar a voz de um aluno e destituí-lo de poder (GIROUX; MCLAREN, 1995, p. 137).

A introdução nos currículos de temáticas ligadas às culturas silenciadas ou negadas reservando-as às datas comemorativas, os “currículos turísticos” (SANTOMÉ, 1995), por um lado, insulariza modos específicos de expressão, histórias de vida, narrativas e linguagens, bem como, os pertencimentos étnicos, de classe, de religião e de gênero, e, por outro, reforça a fragmentação e o 
reducionismo nos processos educativos incidentes sobre a formação e o empoderamento dos sujeitos. Uma possível armadilha para as diferenças culturais é que seja uma temática introduzida apenas pela transmissão dos conteúdos nas aulas e atividades educativas como simples reforço informativo, tratando-se de um saber oco, não-integrado nem implicado. Antes de mais, como defende Santomé (1995, p. 172) "um currículo anti-marginalização é aquele em que todos os dias do ano letivo, em todas as tarefas acadêmicas e em todos os recursos didáticos estão presentes as culturas silenciadas". E isto supõe que a escola busque novas formas de conceber e (re)significar o currículo reconhecendo a condição dos sujeitos nas relações que estabelecem com o todo social e material, como seres inconclusos nas feituras da existência, das experiências, nos modos que inspiram e desafiam a compreensão da realidade:

[...] não podemos considerá-la (a escola) como um dado universal, com um sentido único, principalmente quando este é definido previamente pelo sistema ou pelos professores. Dizer que a escola é polissêmica implica levar em conta que seu espaço, seus tempos, suas relações podem estar sendo significados de forma diferenciada, tanto pelos alunos, quanto pelos professores, dependendo da cultura e projeto dos diferentes grupos sociais nela existentes (DAYRELL, 1996, p. 144).

Assumir tal polissemia nas feituras do currículo reclama a promoção de espaços de diálogo, de abertura ao outro numa atmosfera democrática, onde também,

[...] as representações de gênero, raça, classe, nação, contidas no currículo devem ser subvertidas, desconstruídas, disputadas. É através desse processo de contestação que as identidades hegemônicas constituídas pelos regimes atuais de representação podem ser desestabilizadas e implodidas. O currículo será, então, não apenas um regime de representação, mas um campo de luta pela representação. O currículo poderá, então, conter representações que contem histórias bem diferentes das urdidas pelas relações existentes de poder (SILVA, 1995, p. 201).

Estas representações estão inerentemente associadas ao caráter intercultural do currículo e precisam ser levadas em conta, já que a representação é um processo de produção de significados sociais emanados de discursos distintos. As representações situam-se num campo complexo de disputa, portanto, traduzem valores, "verdades" instituídas e formas de poder. Em vista disso, interessa-nos as perguntas: sob qual discurso e narrativa estas representações têm sido inspiradas e construídas? Quais representações são hegemônicas no currículo? A quem o currículo dá o direito de contar sua história? A configuração do currículo, dessa maneira, passa por uma decisão política (SACRISTÁN, 2000) que implicará na manutenção ou não da hegemonia dominante das representações válidas e aceitáveis, dos valores e comportamentos formulados no bojo das produções culturais e sociais. Nesta linha argumentativa, o currículo constitui-se também como um 
instrumento de resistência e transformação de padrões socioculturais dominantes, cabendo à escola pública - pensada e construída pela participação das diferentes vozes que a constituem - o trabalho, em especial, de modificar a lógica curricular dominante na tentativa de desestabilizar referências sedimentadas como via única.

E participação tem a ver com mediação humana, visto que para Bordenave (1989, p. 16) “a participação não é somente um instrumento para solução de problemas mas, sobretudo, uma necessidade fundamental do ser humano". A participação na escola consiste num processo que se desenvolve mediante ações entrelaçadas à dimensão política, consequentemente, não é um processo de concessão, mas um imperativo de democratização das relações sociais neste espaço público. Estabelecida e reconhecida como prática política, a participação pode propiciar o esgarçamento da hierarquização que encerra tradicionalmente os movimentos de decisão e gestão curricular. A participação torna-se elemento-chave no sentido de horizontalizar as relações de poder, de democratizar as decisões, enfim, de conhecer e intervir na realidade.

A Constituição Federal de 1988 incorporou preceitos fundamentais no que tange à diversidade cultural. Neste diploma legal, a educação é um direito de todos, dever do Estado e da família. O artigo 215 resguarda "o pleno exercício dos direitos culturais e acesso às fontes da cultura nacional" competindo ao estado apoiar "a valorização e a difusão das manifestações culturais". Também está assegurado, neste artigo, como dever do Estado, o de proteger as "manifestações das culturas populares, indígenas e afro-brasileiras, e das de outros grupos participantes do processo civilizatório nacional". Posteriormente, inspirados na Constituição, um conjunto de leis, diretrizes e um extenso aparato normativo reiteram e vem reafirmando o compromisso para com os saberes e as práticas que constituem as diferentes identidades socioculturais: a Lei de Diretrizes e Bases da Educação Nacional nº. 9394/96, a Lei no 10.639/03 que inclui a obrigatoriedade no currículo da História e Cultura Afro-Brasileira, a Lei 11.645/08 que ratifica a cultura indígena, as Diretrizes Curriculares Nacionais para Educação das Relações ÉtnicoRaciais e para o Ensino de História e Cultura Afro-Brasileiras e Africanas, entre outros. Evocar este contexto, já bastante conhecido, vem a propósito em um sentido ilustrativo para acentuar que, a partir destes instrumentos, avanços e novos rumos foram se configurando e sendo interiorizados na produção das políticas educacionais no país, como também são multifacetados os desafios que colocam.

A escola é desafiada a redescobrir meios de encadeamentos da cultura com o currículo podendo reinventar, assim, outras possibilidades de educação como prática social e reconstruir-se como espaço público plural, onde eticamente as particularidades possam ser respeitadas, sentidas, 
representadas, discutidas, combinadas. Conforme Imbernón (2002, p. 82) "assumir a diversidade supõe reconhecer o direito à diferença como um enriquecimento educativo e social". Reconhecer as diferenças compreende lidar com as múltiplas dimensões e complexidades das interações entre sujeitos culturais diferentes, colocando-nos de forma consciente sobre a constituição das alteridades, sobretudo, no sentido de uma conscientização que, para Freire (1980, p. 26) "implica, pois, que ultrapassemos a esfera espontânea de apreensão da realidade, para chegarmos a uma esfera crítica na qual a realidade se dá como objeto cognoscível e na qual o homem assume uma posição epistemológica". Até que ponto o currículo escolar, que diz respeito aos percursos formativos, responde aos anseios, desejos e interesses de uma educação que atenda às demandas sociais de reconhecimento das diferenças e que forja, certamente, mudanças no foco dado à cultura escolar, visto que se observa a escola inserida em um contexto sociocultural marcado por desigualdades e exclusões, inclusive, no próprio processo de escolarização? É uma questão que se impõe fortemente. Implica, por ventura, transformação no escopo administrativo, didáticopedagógico e curricular que regula a instituição escolar, ou seja, num projeto educativo mais global, compartilhado e contextual a fim de que sejam superados modelos educativos segregadores, colonizadores e de subalternização.

Desta forma, outra lógica curricular pode ser instaurada. Assumida como projeto compartilhado, participativo e que se deseja potencialmente democrático, poderá movimentar outros saberes, outros modos de ver a realidade necessários à formação dos sujeitos. O pressuposto do diálogo como um importante alicerce curricular contribui para a desconstrução de modelos unívocos no processo de escolarização, podendo suscitar a valorização de sujeitos culturais e as subjetividades múltiplas que encarnam. Pensar a relação pedagógica, sob uma ótica binária que separa homem x mulher, índio x branco, centro x periferia etc., dificulta a compreensão das relações complexas e de poder que se dão entre cada uma das partes (SILVA, 2000). Portanto, o diálogo é esta exigência do humano para que a relação pedagógica não seja obscurecida por um binarismo fatalista e essencialista.

O papel do currículo escolar é de tal forma fulcral. Nos conhecimentos veiculados através do currículo, o capital cultural dos sujeitos da relação pedagógica deve ser considerado, ou seja, aqueles elementos ligados estreitamente ao mundo que os circunda, às condições estruturais, à natureza social da linguagem que os constituem (Arroyo, 2013). O currículo edificado no encontro, no diálogo, no confronto, na construção intersubjetiva caracteriza-se como promissor para a formação cidadã. O diálogo, instrumento da produção cotidiana do currículo, na visão de Freire (2005, p. 91): 
[...] é uma exigência existencial. E, se ele é o encontro em que se solidarizam o refletir e o agir de seus sujeitos endereçados ao mundo a ser transformado e humanizado, não pode reduzir-se a um ato de depositar ideias de um sujeito no outro, nem tampouco tornar-se simples troca de ideias a serem consumidas permutantes.

O diálogo é compreendido como intercâmbio, como ação-reflexão permanente na relação pedagógica. Supõe a capacidade de escuta e possibilidade de realizar novas conexões, e por isso instiga o empreendimento de um clima escolar afirmativo. Os repertórios culturais, para um currículo intercultural crítico, são mediadores dos processos de ensinar e de aprender, quer na sua dimensão material, quer simbólica, pois configuram as diferentes identidades sociais e culturais dos(as) alunos(as), além de favorecer aprendizagens mais significativas.

Portanto, o conhecimento curricular não deve somente expressar os conteúdos socialmente aceitos como válidos (geralmente os acadêmico-científicos), como também interiorizar àqueles oriundos dos contextos, das vivências e das produções culturais e sociais que marcam as trajetórias identitárias dos(as) alunos(as). Não podemos perder de vista que os conteúdos corporizados no currículo refletem um poder de reprodução que se afilia aos interesses de determinados grupos sociais e culturais, designadamente os conhecimentos reverberadores dos poderes instalados. Apesar disso, estes conteúdos também podem instituir processos de transformação do poder, na medida em que outros conhecimentos são problematizados, contextualizados e integrados à vida escolar dos(as) estudantes porque são compreendidos como recursos pedagógicos necessários a uma efetiva inclusão suportada na assunção de novos arranjos curriculares comprometidos com todos e com cada um; para que os(as) estudantes possam se apropriar dos instrumentos essenciais que os ajudem a atuar plenamente na realidade, a partir de pontos de vista mais críticos e abertos, compreendendo como sócio-historicamente são desenvolvidos regimes geradores de desigualdade e de discriminação no corpo social.

\section{CONSIDERAÇÕES FINAIS}

Neste texto, buscamos enfatizar que um currículo de caráter intercultural crítico, sensível às diferenças culturais, constitui-se num artefato complexo que implica em múltiplas articulações movidas pelo interesse de apontar caminhos para um projeto de sociedade que se contraponha à homogeneização, aos estereótipos e aos padrões culturais hegemônicos e marginalizadores. O universo cultural dos educandos e das educandas torna-se elemento-chave para a promoção de práticas educativas interculturalmente situadas. A construção de um projeto pedagógico-curricular que contemple a participação de todos, sendo os saberes, as experiências e os fazeres respeitados e 
valorizados, assegurando as diferentes formas de pensar, de agir e de se apropriar do mundo, permite que se elabore e favoreça a construção de um currículo democrático e mais justo. No contexto escolar, o currículo vai sendo corporificado nos embates travados entre "intenções e realidades, impregnados por um horizonte que recusa o congelamento das identidades e o preconceito contra aqueles percebidos como diferentes" (CANEN, 2010, p. 192).

A educação intercultural precisa sim estar "colada" aos contextos das lutas dos grupos culturalmente minoritários. Esta prerrogativa representa descortinar a lógica pela qual os significados são atribuídos aos grupos, às pessoas, tanto dentro como fora da escola, com o propósito de construir espaços onde diferentes vozes culturais possam colocar-se abertamente, exprimindo àquilo que lhe é específico e singular, entrecruzando posições e ações, e superando fronteiras bem demarcadas pelas hierarquizações e relações desiguais de poder. De fato, é um caminho de diálogo e de inclusão, onde as diferentes identidades articulam-se no espaço da escola, um espaço-tempo comum e partilhado na construção e reconstrução curricular. Um currículo interculturalmente crítico, entre outras coisas, é um dos caminhos que permitem a aproximação e intersecção dos saberes dos diferentes grupos sociais e culturais; das tradições, das crenças, dos valores, das linguagens e das representações que os diferentes grupos carregam, sendo necessário que as situações curriculares e didático-pedagógicas sejam confrontadas e reatualizadas face a estas diferenças, sobretudo, com a finalidade de neutralizar qualquer estrutura deletéria e insistente de discriminação, de segregação simbólica, de alienação ou de exclusão social.

\section{REFERÊNCIAS}

ARROYO, M. Currículo: território em disputa. 5. ed. Petrópolis, RJ: Vozes, 2013.

BORDENAVE, J. E. D. O que é participação. 6. ed. São Paulo: Brasiliense, 1989.

BOURDIEU, P. O poder simbólico. Rio de janeiro: Editora Bertrand Brasil, 1989.

BRASIL. Lei 9.394, de 20 de dezembro de 1996. Estabelece as diretrizes e bases da educação nacional. Diário Oficial da União. Brasília: Poder Legislativo, 23 dez. 1996, sec. I, n. 248, p. 27.833.

CANDAU, V. M. Cotidiano escolar e práticas interculturais. Cadernos de Pesquisa, v.46, n. 161, p. 802-820, jul./set. 2016.

Direitos humanos, educação e interculturalidade: as tensões entre igualdade e diferença. Revista Brasileira de Educação, Rio de Janeiro, v. 13, n. 37, p. 45-56, 2008.

. (Org.). Educação intercultural e cotidiano escolar. Rio de Janeiro: 7 Letras, 2006.

. (Org.). Sociedade, educação e cultura(s): questões e propostas. Petrópolis, RJ: Vozes, 2002.

Vozes, 2000.

Interculturalidade e educação escolar. In: CANDAU, V. M. (Org.). Reinventar a escola. 3. ed. Petrópolis, RJ: . (Org.). Magistério: construção cotidiana. Petrópolis: Vozes, 1997.

CANEN, A. Sentidos e dilemas do multiculturalismo: desafios curriculares para o novo milênio. In: LOPES, A. C.; MACEDO, E. (Orgs.). Currículo: debates contemporâneos. 3. ed. São Paulo: Cortez, 2010. 
CORTESÃO, L. Professor: produtor e/ou tradutor de conhecimentos? Trabalhando no contexto do arco-íris sociocultural da sala de aula. Educação e Realidade, Porto Alegre, v. 37, n. 3, p. 719-735, 2012. Disponível em: http://www.ufrgs.br/edu realidade.

DAYRELL, J. A escola como espaço sociocultural. In: DAYRELL, Juarez. (Org.). Múltiplos olhares sobre educação e cultura. Belo Horizonte: UFMG,1996.

FLEURI, R. M. O que significa Educação Intercultural. In: FLEURI, R. M. Educação para a diversidade e cidadania. Módulo 2: Introdução Conceitual - Educação para a Diversidade e Cidadania. Florianópolis: MOVER/NUP/CED/ EAD/UFSC, 2009.

. (Org.). Educação intercultural: mediações necessárias. Rio de Janeiro: DP\&A, 2003.

Desafios à educação intercultural no Brasil: culturas diferentes podem conversar entre si? In: III Seminário de Pesquisa em Educação da Região Sul. Anais.... Porto Alegre: UFRGS/ANPED-CDrom, 2000a, p. 1-15.

. O currículo: entre o relativismo e o universalismo. Educação e Sociedade, v. 21, n. 73, 2000 b.

FREIRE, P. Conscientização: teoria e prática da libertação. Uma introdução ao pensamento de Paulo Freire. $3^{\mathrm{a}}$ ed. São Paulo: Moraes, 1980.

Pedagogia do Oprimido. 46. ed. Rio de Janeiro: Paz e Terra, 2005.

; FAUDEZ, A. Por uma pedagogia da pergunta. Rio de Janeiro: Paz e Terra, 1985.

GIROUX, Henry; MCLAREN, Peter. Formação do professor como uma contra-esfera pública: a pedagogia radical como uma forma de política cultural. In: MOREIRA, A. F.; SILVA. T. T. (Orgs.). Currículo, cultura e sociedade. São Paulo: Cortez, 1995.

GEERTZ, C. A interpretação das culturas. Rio de Janeiro: Guanabara Koogan, 1989.

HALL, S. Identidades culturais na pós-modernidade. Rio de Janeiro: DP\&A Editora,1997.

IMBERNÓN, F. Amplitude e profundidade do olhar: a educação ontem, hoje e amanhã. In: IMBERNÓN, F. (Org.). A educação no século XXI: os desafios do futuro imediato. Porto Alegre: Artes Médicas, 2002.

MOREIRA, A.F.; CANDAU, V.M. Educação escolar e culturas: construindo caminhos. Revista Brasileira de Educação, n. 23, p. 156-168, maio/ago, 2003.

; CANDAU, Vera M. (Orgs.). Multiculturalismo: diferenças culturais e práticas pedagógicas. Petrópolis, RJ: Vozes, 2008.

MORIN, E. Os sete saberes necessários à educação do futuro. São Paulo: Cortez, 2002.

MORIN, E. O método: 4 - As Ideias. Porto Alegre, RG: Sulina, 1998, p. 23-78.

MORGADO, J. C. Democratizar a escola através do currículo: em busca de uma nova utopia. Ensaio: avaliação e políticas públicas em educação, Rio de Janeiro, v. 21, n. 80, p. 433-448, jul./set. 2013.

PACHECO, J. A. Estudos Curriculares: para uma compreensão crítica da educação. Porto: Porto Editora, 2005.

RIGAL, L. A escola crítico-democrática: uma matéria pendente no limiar do século XXI. In: IMBERNÓN, Francisco (Org.). A educação no século XXI: os desafios do futuro imediato. Porto Alegre: Artes Médicas, 2000.

SACRISTÁN. J. G. O currículo: uma reflexão sobre a prática. 3. ed. Porto Alegre: Artes Médicas, 2000.

SANTOMÉ, J.T. As culturas negadas e silenciadas no currículo. In: SILVA, T.T. (Org.). Alienígenas na sala de aula: uma introdução aos estudos culturais em educação. Petrópolis, RJ: Vozes, 1995.

SILVA, T.T. Alienígenas na sala de aula: uma introdução aos estudos culturais em educação. Petrópolis, RJ: Vozes, 1995.

Territórios contestados: o currículo e os novos mapas políticos e culturais. Petrópolis, RJ: Vozes, 2001.

SILVA, T.T. A nova direita e as transformações na pedagogia da política e na política da pedagogia. In: GENTILI, P.; SILVA, T.T. (Orgs.). Neoliberalismo, qualidade total e educação. 11. ed. Petrópolis, RJ: Vozes, 2002. 


\section{RESUMO}

No presente artigo refletimos sobre o currículo escolar numa perspectiva intercultural crítica baseando-nos, especialmente, em Fleuri, Candau, Moreira e Candau. O currículo como projeto formativo torna-se um instrumento poderoso na luta por superar visões monoculturais, monolíticas e redutoras que constrangem práticas anti-discriminatórias, de abertura e de diálogo com as diferenças e diversidades culturais. Nesta conformidade, um currículo intercultural crítico consiste em fomentar concepções, estratégias, métodos e ações educativas fundamentadas em valores tais como solidariedade, pluralidade e democracia, substancialmente relevantes, ou seja, como uma proposta que se perfila mais do que pedagógica, ética e político-social.

Palavras-chave: Escola. Currículo. Perspectiva intercultural crítica.

\section{INTERCULTURAL CRITICAL CURRICULUM AT SCHOOL: EDUCATION THAT MAKES A DIFFERENCE ABSTRACT}

The present article reflects the intercultural perspective of the school curriculum based mainly on Fleuri, Candau, Moreira e Candau. Curriculum as a school project becomes a powerful tool to overcome monocultural, monolithic and reductive visions which constrain anti-discriminatory practice, of opening and dialogue with cultural differences and diversities. In conformity to that, an intercultural curriculum consists of promoting notions, strategies, methods and educative actions based on values as solidarity, plurality and democracy, substantially compatibles with a ethic and social-political proposal, more than with a pedagogic one.

Keywords: School. Curriculum. Intercultural critical perspective.

\section{CURRÍCULO INTERCULTURAL CRÍTICO EN LA ESCUELA: FORMACIÓN QUE PRODUCE DIFERENCIAS RESUMEN}

En el presente artículo reflexionamos sobre el currículo escolar en una perspectiva intercultural crítica basándonos, especialmente, en Fleuri, Candau, Candau y Moreira. El currículo como proyecto formativo se convierte en un instrumento poderoso en la lucha por superar visiones monoculturales, monolíticas y reductoras que limitam prácticas antidiscriminatorias, de apertura y de diálogo con las diferencias y diversidades culturales. En consecuencia, un currículo intercultural crítico consiste en fomentar concepciones, estrategias, métodos y acciones educativas fundamentadas en valores tales como solidaridad, pluralidad y democracia, sustancialmente relevantes como una propuesta que se muestra más que pedagógica, ética, política y social.

Palabras-clave: Escuela. Currículo. Perspectiva intercultural crítica. 